\title{
Reply to the Letter-to-the-Editor of Dr. García-Toraño regarding article "Improving Alpha Spectrometry Energy Resolution by Ion Implantation with ICP-MS", DOI: 10.1007/s10967-014-3500-8
}

\author{
Michael Dion ${ }^{1}$
}

Received: 14 April 2015/Published online: 2 June 2015

(C) Akadémiai Kiadó, Budapest, Hungary 2015

Dear Dr. Revay,

While I appreciate the comments presented by Dr. García-Toraño it is inaccurate to state that gross differences in alpha sample preparation techniques are only observable in high resolution systems as this work (and others) has shown that differences in sample development can be discriminated with large area, low-resolution detectors. Furthermore, it was directly stated that future research would be conducted with high-resolution silicon based alpha spectroscopy. Pertaining to the research under question, we compared two "standard" sample preparation techniques to a new and exciting method using available large area detectors maintained in our count lab. This allowed publication in a timely fashion while, in parallel, a high resolution system was developed. We do not have the capability of vacuum evaporation or other recent sample development methods. And in fact, the author/s never concluded that the ICP-MS samples would be superior to the aforementioned techniques, only that there was a repeatable observed improvement in energy resolution when compared to two other standard techniques.

Sincerely, Michael Dion, PhD.
This is a reply to the letter to the Editor of article doi: 10.1007/ s10967-014-3500-8.

Michael Dion

michael.dion@pnnl.gov

1 Pacific Northwest National Laboratory, Richland, WA, USA 